\title{
Interconnection of Distributed Generation Resources to Three-phase Four-wire Grids using a Novel Control Technique
}

\author{
S. Sajjad Seyedalipour ${ }^{*}$, Gevork B. Gharehpetian ${ }^{2}$, Moslem Darvishi ${ }^{3}$ and Habib Allah Aalami ${ }^{4}$ \\ 'Department of Electrical Engineering, K. N. Toosi University of Technology, Tehran, Iran; sseyedalipour@gmail.com \\ 2Department of Electrical Engineering, Amirkabir University of Technology, Tehran, Iran; grptian@aut.ac.ir \\ 32Department of Electrical Engineering, Imam Hossein University, Tehran, Iran; darvishimoslem@gmail.com \\ ${ }^{4}$ Department of Electrical Engineering, Eyvanekey University, Tehran, Iran; h.aalami41@eyc.ac.ir
}

\begin{abstract}
Objectives: Power electronic converters are usually utilized for interfacing Distributed Generation (DG) resources to power grids. This paper proposes a novel and simple control technique for connection of DG resources to Three-Phase Four-Wire (3P4W) distribution grids via interfaced converters. Methods: The differential equations of the DG system are established, and then the switching state functions of the grid-interfacing converter are achieved in order to improve the transient response of system and power quality of grid. Results: By means of the proposed approach, the grid-interfacing converter can transfer active power at main frequency from DG resources to grid, and also compensate all reactive, neutral, harmonic and unbalanced load current components with a fast transient waveform. Applications: The effectiveness of the proposed control technique is demonstrated by the simulation studies in MATLAB/Simaulink environment.
\end{abstract}

Keywords: Distributed Generation (DG), Grid-interfacing Converter, Power Quality, Three-phase Four-wire (3P4W) Distribution Grid

\section{Introduction}

Electrical power grids are getting increasingly stressed because of the increment in the power consumption and also limitations on power transmission and subtransmission systems. Power injection from Distributed Generation (DG) resources (specially based on renewable) to distribution grids during the peak of power demand can decrease the stress from the grid's point of view and the cost of power consumption from the customer's point of view. But, the high penetration level of DG resources in power grid may cause problems in the management and proper operation of the entire power system $^{1-3}$.

In DG systems, the power electronic converters are essential interfaces to connect DG resources to power grid $^{4}$. Since DG unit must not adjust the voltage at the
Point of Common Coupling (PCC) as specified through the IEEE standards ${ }^{5}$, the current control of grid-interfacing converters plays an important role in enhancing power quality of grid. Thus, development of power electronic converters and its high-performance controllers make it possible to connect various kinds of DG resources to electrical power grids.

Numerous studies have been reported in the literature regarding the control of grid-interfacing converters for integration of DG resources to grid $^{6-10}$. For instance, a comprehensive review on the topologies and control strategies of grid-interfacing converters has been presented in $^{11}$. In ${ }^{12}$, a control strategy has been suggested to mitigate the impact of DG resources on the protection coordination. The proposed approach could limit the current injected from the grid-interfacing converter with regard to the DG unit terminal voltage. A cooperative imbalance 
compensation technique for grid-interfacing converters has been designed via computation of negative sequence reactive power ${ }^{13}$. Based on adaptive linear neuron control, the grid-interfacing converter has been used to not only control the active power at main frequency, but also to mitigate the harmonic and unbalanced currents of the load, and to manage the reactive power flow of the network $^{14}$. A static var compensator by means of three-level gate turn-off thyristor converter has been discussed in ${ }^{15}$ for high-voltage, high-power applications. In the proposed model of this paper, the design of the controller has been carried out through the small-signal model. The proposed model do not have an overall description of the dc-link side and the ac side dynamics. $\operatorname{In}^{16,17}$, the hysteresis current controllers for grid-interfacing converters have been addressed. These schemes have the capability to transfer power generated by DG resources to grid and also to operate as a power quality compensator.

In this paper, a novel control technique is proposed for the proper and stable operation of the DG unit in Three-Phase Four-Wire (3P4W) distribution grids. The proposed technique removes overshoot during transientstate condition and provides a short response time. In addition, the proposed approach in DG application can be used for the compensation of different issues under the connection of unbalanced nonlinear reactive loads to network.

\section{System under Study}

Figure 1 shows the configuration of the system considered in this paper. The system consists of three main parts i.e., 3P4W grid, loads and DG unit. Three-phase and/ or single-phase (non) linear (re)active loads are connected at the local bus. The DG unit is integrated to the grid in shunt connection type, which injects required current components to the PCC via a three-phase fourleg Voltage Source Converter (VSC) used as interface between the DG Park and the network. The DG park illustrated in Figure 1 can include numerous dispatch able DG resources (such as fuel cell, photovoltaic, storage, etc). It can be seen that the interfaced VSC is connected to the PCC through the resistance $R D G$ and inductance $L D G$ of the DG unit filter. $i_{g_{a}}, i_{g_{b}}, i_{g_{c}}$ and $i_{g_{n}}$ are the grid currents, $i_{D G_{a}}, i_{D G_{b}}, i_{D G_{c}}$ and $i_{D G_{n}}$ are the DG unit currents, $i_{l_{a}}, i_{l_{h}}, i_{l_{c}}$ and $i_{l_{n}}$ are the load currents, $V_{P C C_{a}}, V_{P C C_{b}}$ and $V_{P C C_{c}}$ are the PCC voltages, $C_{d c}$ is the dc-link capacitor and $v_{d c}$ is the dc-link voltage.

The averaged model of the grid-interfacing VSC can be given in the $a b c$ frame by:

$$
\begin{aligned}
& R_{D G} i_{D G_{a}}+L_{D G} \frac{d i_{D G_{a}}}{d t}+V_{P C C_{a}}=v_{a M}+v_{M N} \\
& R_{D G} i_{D G_{b}}+L_{D G} \frac{d i_{D G_{b}}}{d t}+V_{P C C_{b}}=v_{b M}+v_{M N}
\end{aligned}
$$

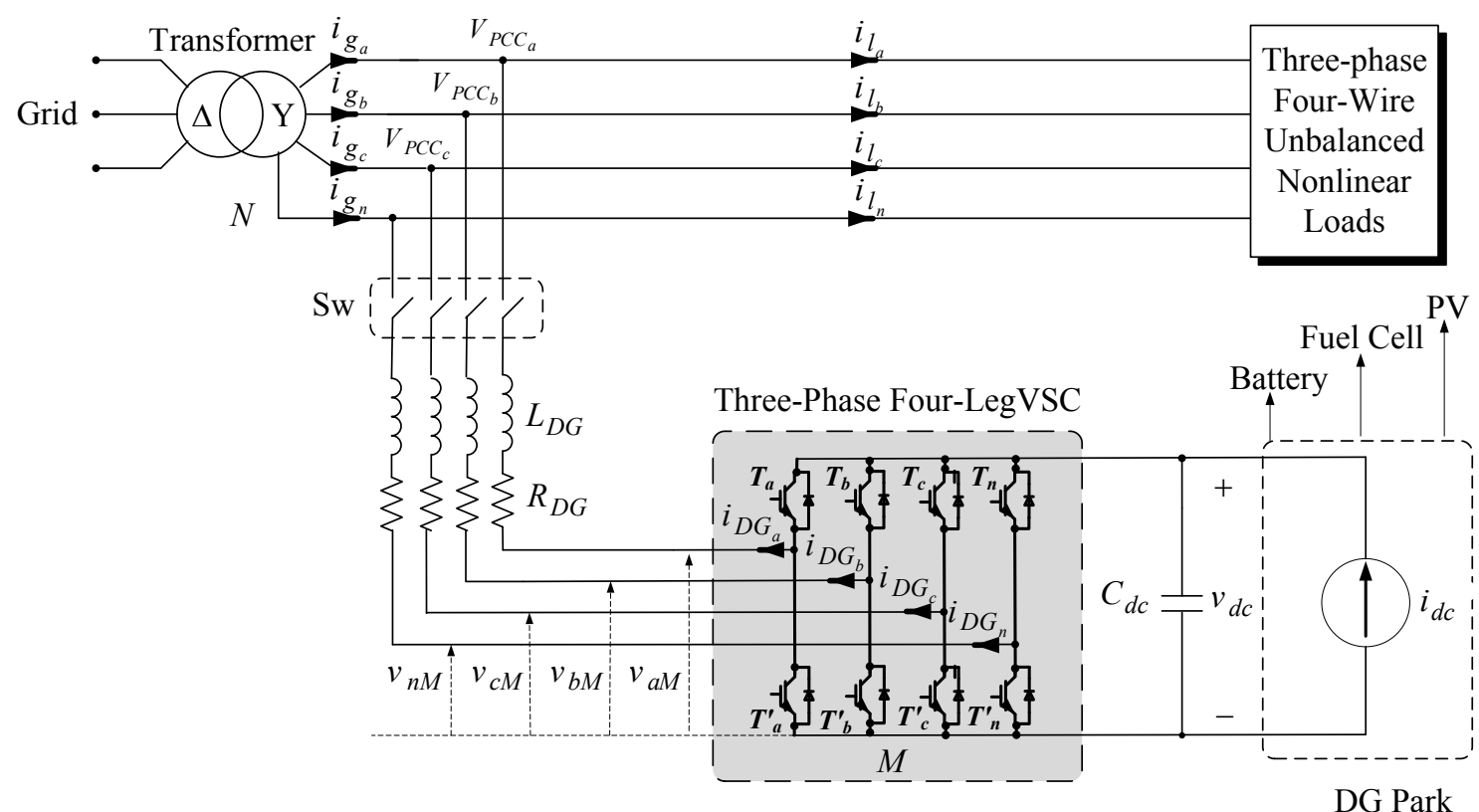

Figure 1. System configuration. 


$$
\begin{aligned}
& R_{D G} i_{D G_{c}}+L_{D G} \frac{d i_{D G_{c}}}{d t}+V_{P C C_{c}}=v_{c M}+v_{M N} \\
& R_{D G} i_{D G_{n}}+L_{D G} \frac{d i_{D G_{n}}}{d t}=v_{n M}+v_{M N}
\end{aligned}
$$

where, $v_{M N}$ is the voltage between point $M$ and $N$. Summation of four parts in Equation (1), it gives:

$$
\begin{array}{r}
R_{D G} \sum_{j=a}^{b, c, n} i_{D G_{j}}+L_{D G} \frac{d}{d t}\left(\sum_{j=a}^{b, c, n} i_{D G_{j}}\right) \\
+\sum_{j=a}^{b, c} V_{P C C_{j}}=\sum_{j=a}^{b, c, n} v_{j M}+4 v_{M N}
\end{array}
$$

With the assumption that the voltages at PCC are ideal during the operation of the DG system, we can write:

$$
V_{P C C_{a}}+V_{P C C_{b}}+V_{P C C_{c}}=0
$$

On the other hand, we have:

$$
i_{D G_{a}}+i_{D G_{b}}+i_{D G_{c}}+i_{D G_{n}}=0
$$

Hence:

$$
v_{M N}=-\frac{1}{4} \sum_{j=a}^{b, c, n} v_{j M}
$$

The switching function $S k(k=a, b, c, n)$ of the VSC can be defined as follows:

$$
S_{k}=\left\{\begin{array}{l}
1, \text { if } T_{k} \text { is on and } T^{\prime}{ }_{k} \text { is off } \\
0, \text { if } T_{k} \text { is off and } T^{\prime}{ }_{k} \text { is on. }
\end{array}\right.
$$

where, the VSC gating signals $T k$ and $T$ ' $k$ are binary values generated by Sinusoidal Pulse Width Modulation (SPWM). So, by writing $v_{k M}=S_{k} v_{d c}$, Equation (1) becomes:

$$
R_{D G} i_{D G_{a}}+L_{D G} \frac{d i_{D G_{a}}}{d t}+V_{P C C_{a}}=\left(S_{a}-\frac{1}{4} \sum_{j=a}^{b, c, n} S_{j}\right) v_{d c}
$$

$$
\begin{aligned}
& R_{D G} i_{D G_{b}}+L_{D G} \frac{d i_{D G_{b}}}{d t}+V_{P C C_{b}}=\left(S_{b}-\frac{1}{4} \sum_{j=a}^{b, c, n} S_{j}\right) v_{d c} \\
& R_{D G} i_{D G_{c}}+L_{D G} \frac{d i_{D G_{c}}}{d t}+V_{P C C_{c}}=\left(S_{c}-\frac{1}{4} \sum_{j=a}^{b, c, n} S_{j}\right) v_{d c} \\
& R_{D G} i_{D G_{n}}+L_{D G} \frac{d i_{D G_{n}}}{d t}=\left(S_{n}-\frac{1}{4} \sum_{j=a}^{b, c, n} S_{j}\right) v_{d c}
\end{aligned}
$$

The switching state function $d k$ of the VSC is expressed by the following equation:

$$
d_{k}=S_{k}-\frac{1}{4} \sum_{j=a}^{b, c, n} S_{j}
$$

Thus, the following relation is deduced:

$$
d_{n}=-\left(d_{a}+d_{b}+d_{c}\right)
$$

A synchronously rotating frame transformation is employed to express the equations of the DG system in a $d q 0$ frame. The transformation matrix is as:

$$
T_{d q 0}^{a b c}(\theta)=\frac{2}{3}\left[\begin{array}{ccc}
\sin (\theta) & \sin (\theta-2 \pi / 3) & \sin (\theta+2 \pi / 3) \\
\cos (\theta) & \cos (\theta-2 \pi / 3) & \cos (\theta+2 \pi / 3) \\
1 / 2 & 1 / 2 & 1 / 2
\end{array}\right]
$$

where, $\theta=\omega t$ and $\omega$ is the angular frequency of the grid.

By considering the direction of the reference vector of the PCC voltage in the direction of $d$-axis, the $q$ - and 0 -components of the PCC voltage are zero. The transformed model in the $d q 0$ reference frame is as follows:

$$
\begin{aligned}
L_{D G} \frac{d i_{D G_{d}}}{d t} & =-R_{D G} i_{D G_{d}}+\omega L_{D G} i_{D G_{q}}-V_{P C C_{d}}+d_{d} v_{d c} \\
L_{D G} \frac{d i_{D G_{q}}}{d t} & =-R_{D G} i_{D G_{q}}-\omega L_{D G} i_{D G_{d}}+d_{q} v_{d c} \\
L_{D G} \frac{d i_{D G_{0}}}{d t} & =-R_{D G} i_{D G_{0}}+d_{0} v_{d c}
\end{aligned}
$$


where, $V_{P C C_{d}}$ is the PCC voltage in $d$-axis; $i_{D G_{d}}, i_{D G_{q}}$ and $i_{D G_{0}}$ are the DG unit currents in $d$-, $q$ - and 0 -axes; $d_{d}, d_{q}$ and $d_{0}$ are the switching state functions of the VSC in $d$-, $q$ - and 0 -axes.

\section{Proposed Technique}

To attain a fast transient waveform to supply load active, reactive, neutral, unbalanced and harmonic currents, Equation (11) should be controlled in three various and independent loops. By writing, $\lambda=L_{D G}\left(d i_{D G} / d t\right)+R_{D G} i_{D G}$, the switching state function of the grid-interfacing VSC (original control inputs) can be achieved in the following form:

$$
\begin{aligned}
& d_{d}=\frac{\lambda_{d}-\omega L_{D G} i_{D G_{q}}+V_{P C C_{d}}}{v_{d c}} \\
& d_{q}=\frac{\lambda_{q}+\omega L_{D G} i_{D G_{d}}}{v_{d c}} \\
& d_{0}=\frac{\lambda_{0}}{v_{d c}}
\end{aligned}
$$

The inputs $d_{d}$ and $d_{q}$ are combination of a nonlinear term and a linear decoupling one. In order to obtain a fast transient waveform and zero steady state errors, a Proportional-Integral (PI) regulator is required. Consequently, Equation (13) can be achieved as follows:
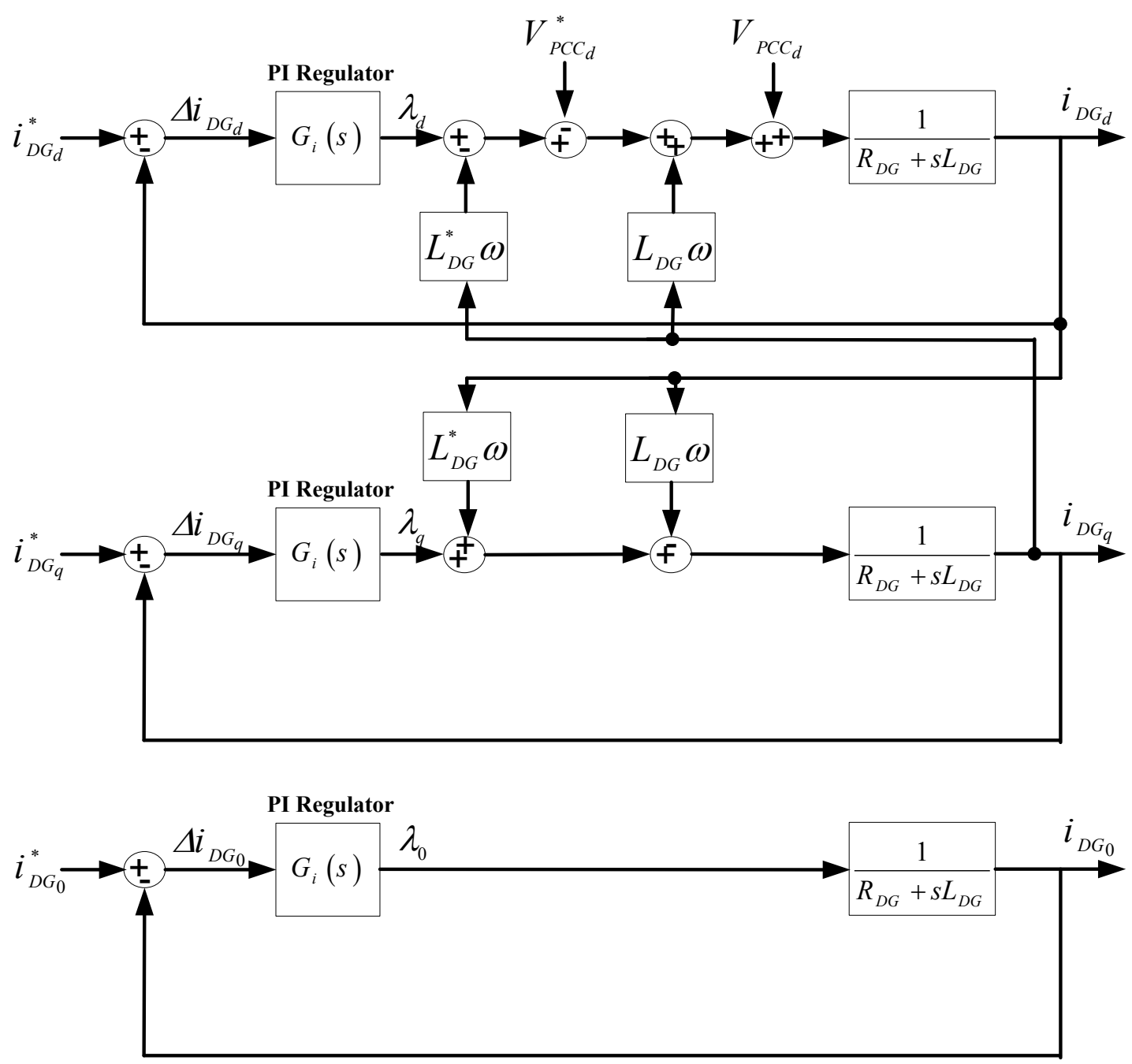

Figure 2. Current control loops. 


$$
\left(\lambda_{d q 0}\right)=k_{p}\left(\Delta i_{D G_{d q 0}}\right)+k_{i} \int\left(\Delta i_{D G_{d q 0}}\right) d t
$$

where, $k_{p}$ and $k_{i}$ are the proportional and integral gains, and $\Delta i_{D G_{d q 0}}=i_{D G_{d q 0}}^{*}-i_{D G_{d q 0}}$ indicates a comparison of the reference current components and the real DG unit currents injected by the grid-interfacing VSC.

The transfer function of PI regulator for the control loops can be obtained by the following equation:

$$
G_{i}(s)=\frac{\lambda_{d q 0}}{\Delta I_{D G_{d q 0}}(s)}=k_{p}+\frac{k_{i}}{s}
$$

In order to design PI regulator, it is needed to decouple the system equations for $d$ - and $q$-axes, by means of adding the $d$-axis measured voltage and crosscoupling parts as illustrated in Figure 2, where $V_{P C C_{d}}^{*}$ and $L_{D G}^{*}$ are the estimated parameters of the PCC voltage and the filter inductance.

Hence, the current control loops are simplified as illustrated in Figure 3. As shown in Figure 2, the current loops for $d$ - and $q$-axes are the same. As a consequence, in the $d q 0$ frame, the decoupled control of active and reactive powers (including harmonic and unbalanced components), and also neutral current is conveniently obtained via separately controlling the currents in $d-, q$ - and 0 -axes.

The transfer function of the current control loop is achieved by the following equation:

$$
\begin{aligned}
& \frac{I_{D G_{d}}(s)}{I_{D G_{d}}^{*}(s)}=\frac{I_{D G_{q}}(s)}{I_{D G_{q}}^{*}(s)}=\frac{I_{D G_{0}}(s)}{I_{D G_{0}}^{*}(s)} \\
& =\frac{k_{p}}{L_{D G}} \frac{s+\frac{k_{i}}{k_{p}}}{s^{2}+\frac{\left(R_{D G}+k_{p}\right)}{L_{D G}} s+\frac{k_{i}}{L_{D G}}}
\end{aligned}
$$

The dynamic waveform of the currents is affected through the zero in Equation (15). For the optimal value of the damping factor $\xi=\sqrt{1 / 2}$, the overshoot is $20.79 \%$. In order to remove the impact of the zero on the dynamic waveform in Equation (15), a Low-Pass Filter (LPF) $G_{p}(s)=1 /\left(s+k_{i} / k_{p}\right)$ is employed as indicated in Figure 4. Therefore, the transfer function of current control loops will be without any zero. In comparison with general equation of a second order transfer function $\omega_{n}^{2} /\left(s^{2}+2 \xi \omega_{n} s+\omega_{n}^{2}\right)$, the proportional and integral gains are calculated as follows:

$$
\begin{aligned}
& k_{p}=2 L_{D G} \xi \omega_{n}-R_{D G} \\
& k_{i}=L_{D G} \cdot \omega_{n}^{2}
\end{aligned}
$$

where, $\omega_{n}$ is the natural undamped angular frequency ${ }^{18}$.

\subsection{Calculation of Reference Current Components}

The reference current components of the DG unit control loop must be determined considering the objectives of the control strategy. Thus, injection of maximum available active power at main frequency, all harmonic currents, neutral current, unbalanced currents, and reactive power of load should be considered in the control loop of the DG unit.

Since the neutral current of the grid should be completely removed, therefore, the 0-component of the DG unit's reference current is equal to the 0 -component of the load current. On the other hand, the DG unit should be able to correct the power factor of the grid. So, the $q$-component of the DG unit's reference current is identical to the $q$-component of the load current.

The rest of the load currents in $d$-axis contains the positive and negative sequence components including harmonic components. The negative sequence and harmonic currents of the load should be exactly extracted

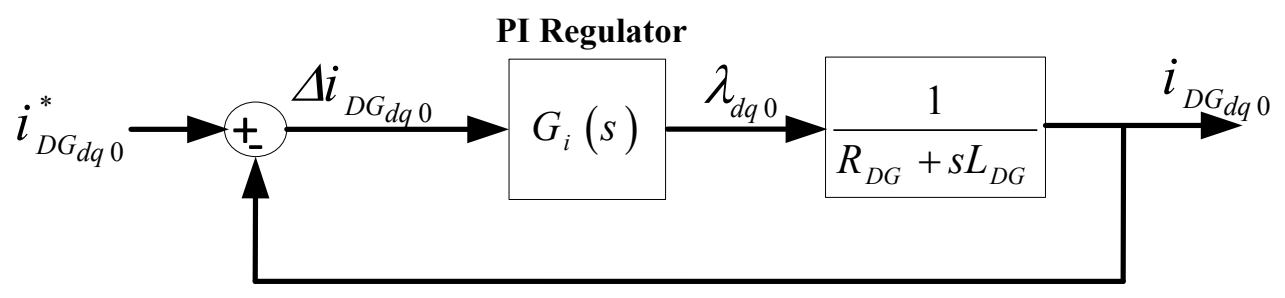

Figure 3. Simplified scheme of current control loops. 


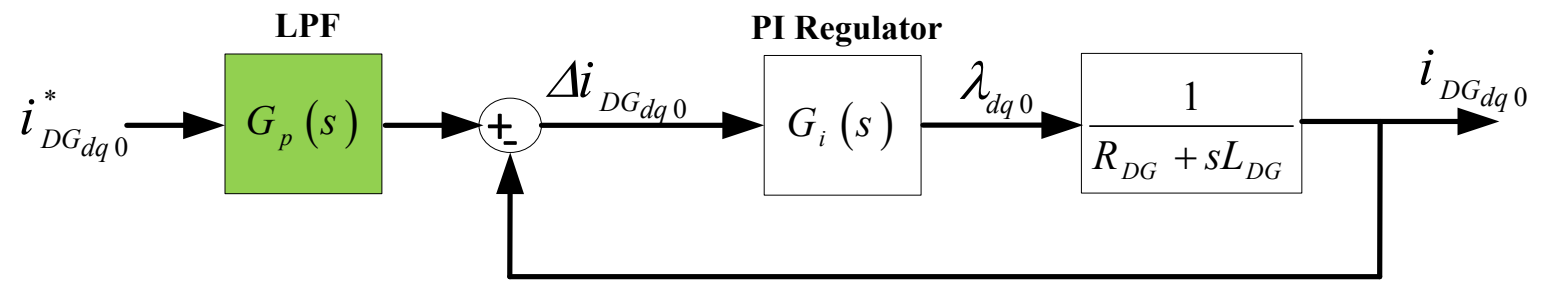

Figure 4. Final scheme of current control loops.

in order to be compensated by the DG unit. In the $d q 0$ reference frame, the harmonic and negative sequence currents of the load appear as an alternative term. As a result, the harmonic and negative sequence currents of the load can be separated by means of a High-Pass Filter (HPF). In order to minimize the influence of the HPF phase response, the HPF can be achieved by using a LPF. However, for the calculation of the $d$-component of the DG unit's reference current, the maximum capacity of the VSC for injection of the active power at the main frequency $\left(P_{\max }\right)$ should be considered. According to the mentioned assumptions, the DG unit's reference currents in the $d q 0$ frame are expressed as follows:

$$
\begin{aligned}
I_{D G_{d}} & =\frac{2}{3} \frac{P_{\max }}{V_{P C C_{d}}}+i_{l_{d}}(1-L P F) \\
I_{D G_{q}} & =i_{l_{q}} \\
I_{D G_{0}} & =i_{l_{0}}
\end{aligned}
$$

where, $i_{l_{d}}, i_{l_{q}}$ and $i_{l_{0}}$ are the load currents in $d-, q$ and 0 -axes, respectively.

\section{Simulation Results}

In order to evaluate the performance of the proposed nonlinear control strategy, a simulation model of the DG system, shown in Figure 5, was simulated by means of the "Power System Blockset" simulator operating in the MATLAB/Simulink environment. The parameters used in the simulation studies are given in Table 1. The maximum active power of the grid-interfacing converter at the main frequency is considered $7 \mathrm{~kW}$, and it is assumed that the converter continuously injects this power.

At first, a single-phase resistive load of $R a=20 \Omega$ in phase $a$, a single-phase resistive-inductive load of $R b=40$ $\Omega$ and $L b=0.15 \mathrm{mH}$ in phase $b$, and a three-phase diode bridge rectifier with resistive load of $R 1=50 \Omega$ are con-
Table 1. System parameters

\begin{tabular}{|l|l|}
\hline Filter resistance & $0.1 \Omega$ \\
\hline Filter inductance & $15 \mathrm{mH}$ \\
\hline Rated dc-link voltage & $800 \mathrm{~V}$ \\
\hline Switching frequency & $12 \mathrm{kHz}$ \\
\hline Grid voltage & $380 \mathrm{~V}$ \\
\hline Grid frequency & $50 \mathrm{~Hz}$ \\
\hline
\end{tabular}

nected to the grid and draw the unbalanced nonlinear reactive currents. This process is continued until $t=0.1$ s. At this instant, the DG unit is connected to the grid. Another three-phase diode bridge rectifier with resistive load of $R 2=30 \Omega$ is added to the initial loads at $t=0.2 \mathrm{~s}$, and disconnected from the grid at $t=0.3 \mathrm{~s}$. Figure 6 illustrates the load, DG unit, and grid currents.

It can be observed that before connection of the DG unit, all the load currents are provided via the grid, but after connection of the DG unit, all the load currents are supplied through the DG unit and the grid current becomes zero. In addition, after connection of the extra load to the network, the power demand of the loads is more than the maximum power of the DG unit; then, the remainder of the power, which is a balanced active power at the main frequency, is provided by the utility grid. Furthermore, Figure 6 shows that after connection of the extra load, current provided from the grid is sinusoidal and balanced. By removing the extra load at $t=0.3$ $s$, all the load currents are injected by the DG unit again.

Figure 7 indicates the currents of load, DG unit and source in similar phases after connection of the extra load to the grid, in order to better show the influences of the DG unit. It is seen that the source currents are sinusoidal and not in phase with the load currents (because of the compensation of the load reactive power through the DG unit).

Figure 8 shows the capability of the DG unit's control loop to track the reference current trajectories of $d-$, q- 


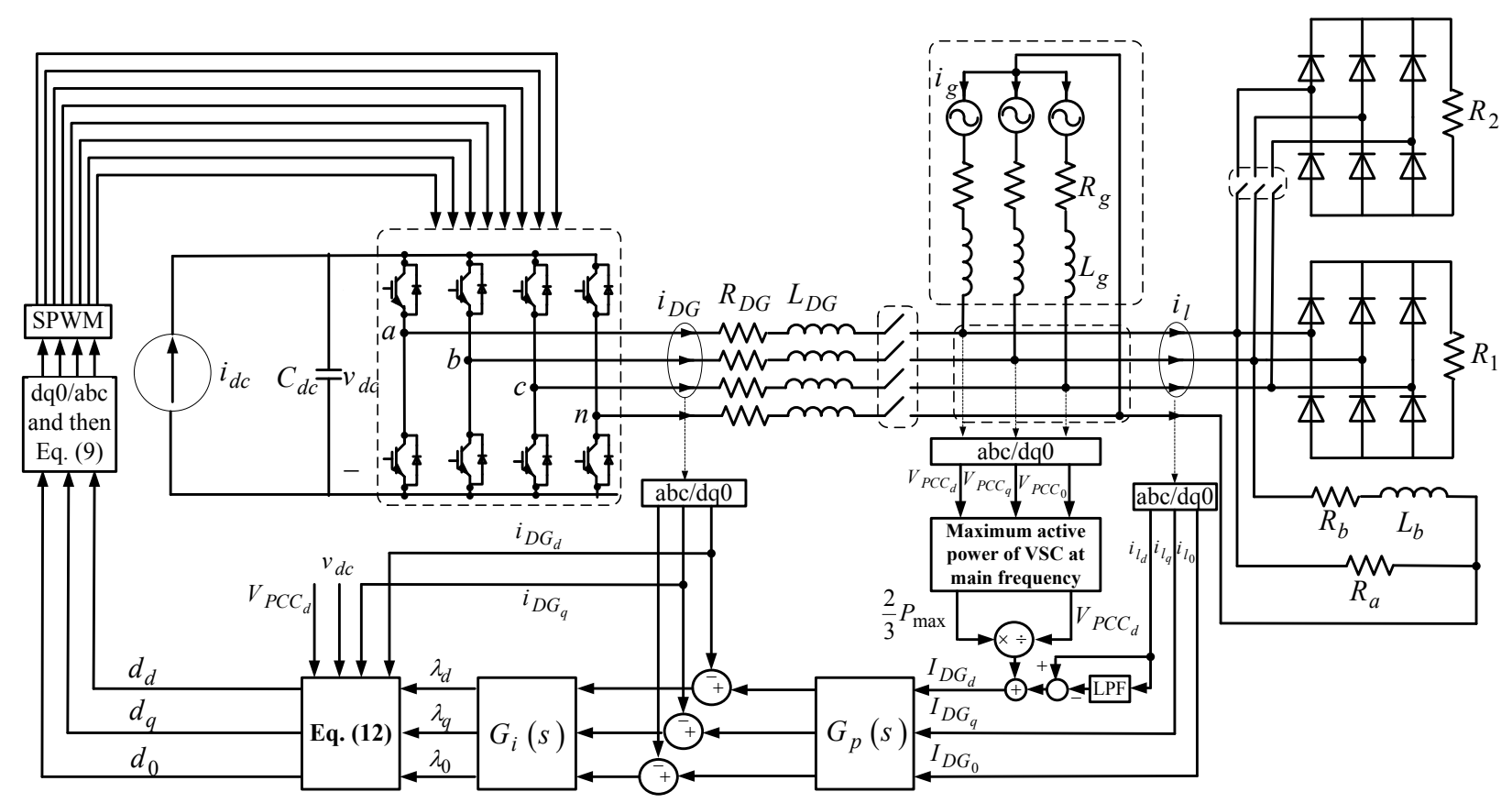

Figure 5. Schematic diagram of the simulated system along with control block diagram.
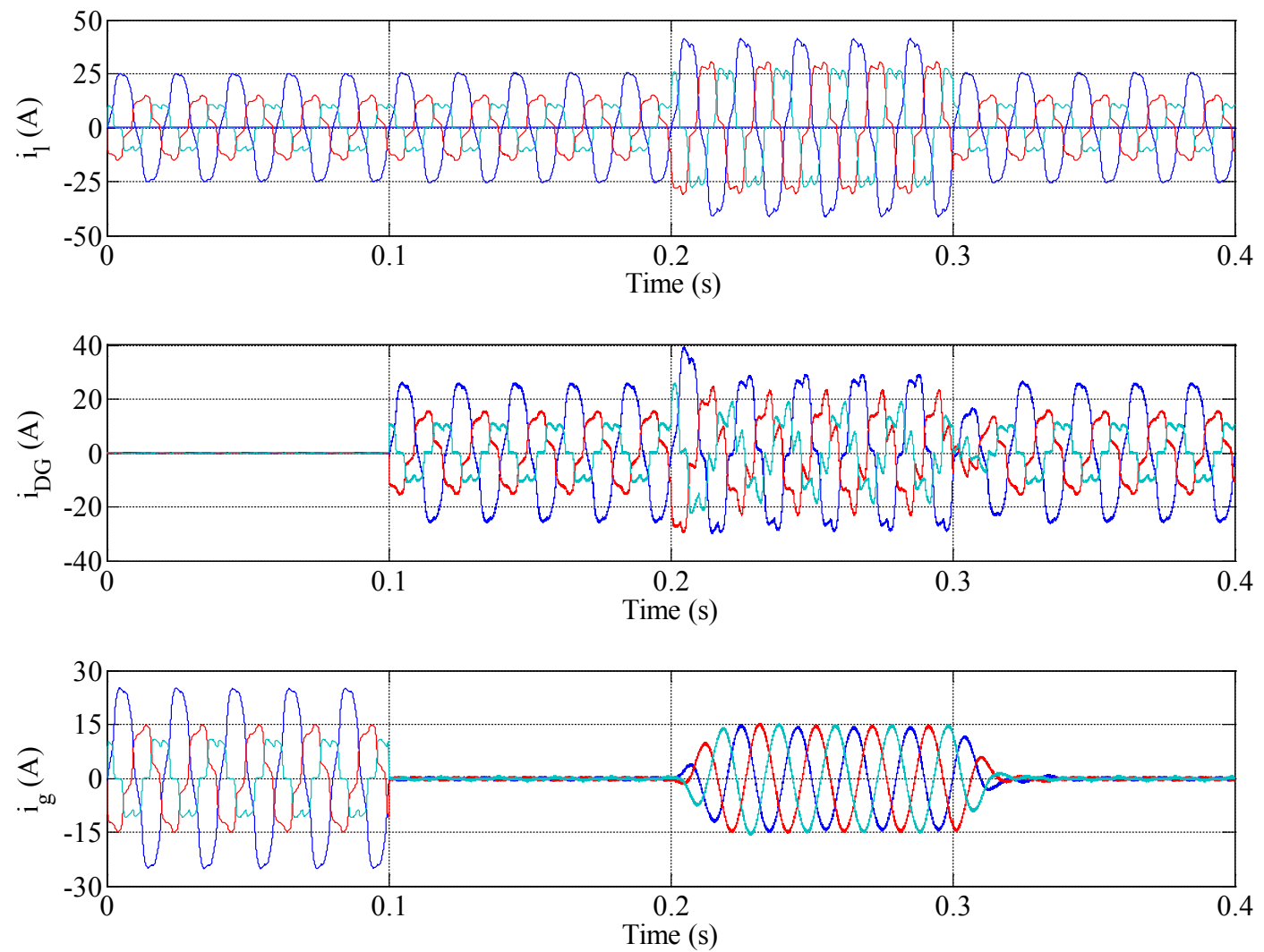

Figure 6. Load, DG unit and grid currents during considered events. 

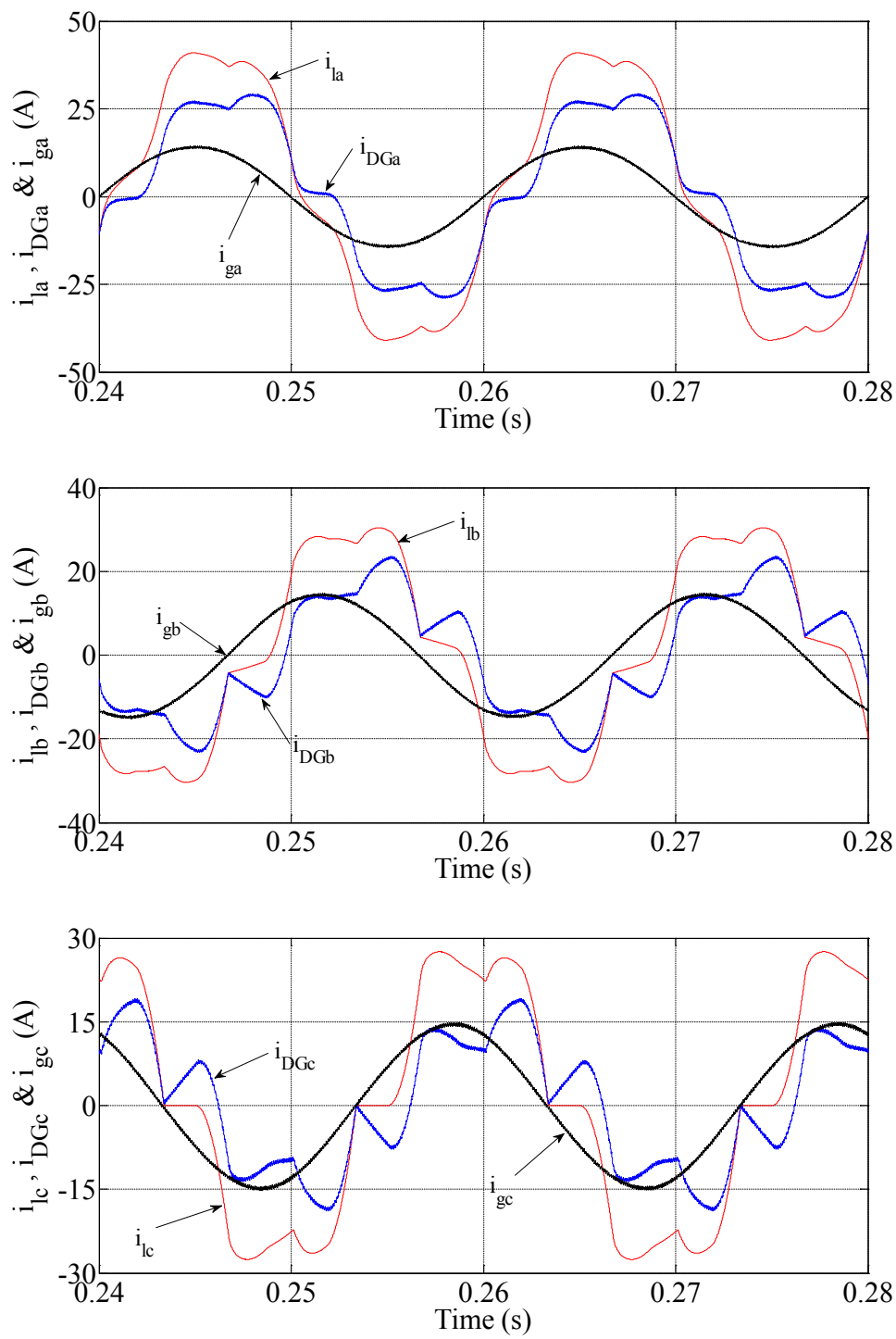

Figure 7. Load, DG unit and grid currents in phases $a, b$ and $c$ after connection of extra load.

and 0 -axes, during the considered events. As can be seen, before connection of the extra load to the grid, the actual $d-, q$ - and 0 -axes currents of the DG unit's control loop exactly track their reference trajectory. After connection of the extra load to the grid, the actual $d$-axis current of the DG unit tracks some of its reference trajectory which is related to the maximum active power of the gridinterfacing converter at the main frequency, and all the reference trajectories of the reactive and neutral current change. As shown, after connection and disconnection of the extra load, the $d$-axis current of the DG unit has a delay of one cycle $(0.02 \mathrm{~s})$. This is because of the settling time of the minimal phase HPF. According to Figure 8, the transient performance of the tracking error is fast and zero steady-state error is achieved.

In order to evaluate the influence of the proposed control strategy for the compensation of the harmonic currents, the spectra of the load and grid currents after connection of the extra load to the grid are shown in Figures 9 and 10. Figure 9 shows that the Total Harmonic Distortions (THDs) of the load currents are $12.33 \%$, $18.51 \%$ and $21.63 \%$ in phases $a, b$ and $c$, respectively. But, the THDs of the source currents are corrected to be $1.93 \%, 1.92 \%$ and $1.92 \%$ in phases $a, b$ and $c$, respectively, as indicated in Figure 10, which are well below the IEEE519-1992 standard requirements (THD<5\%). The com- 

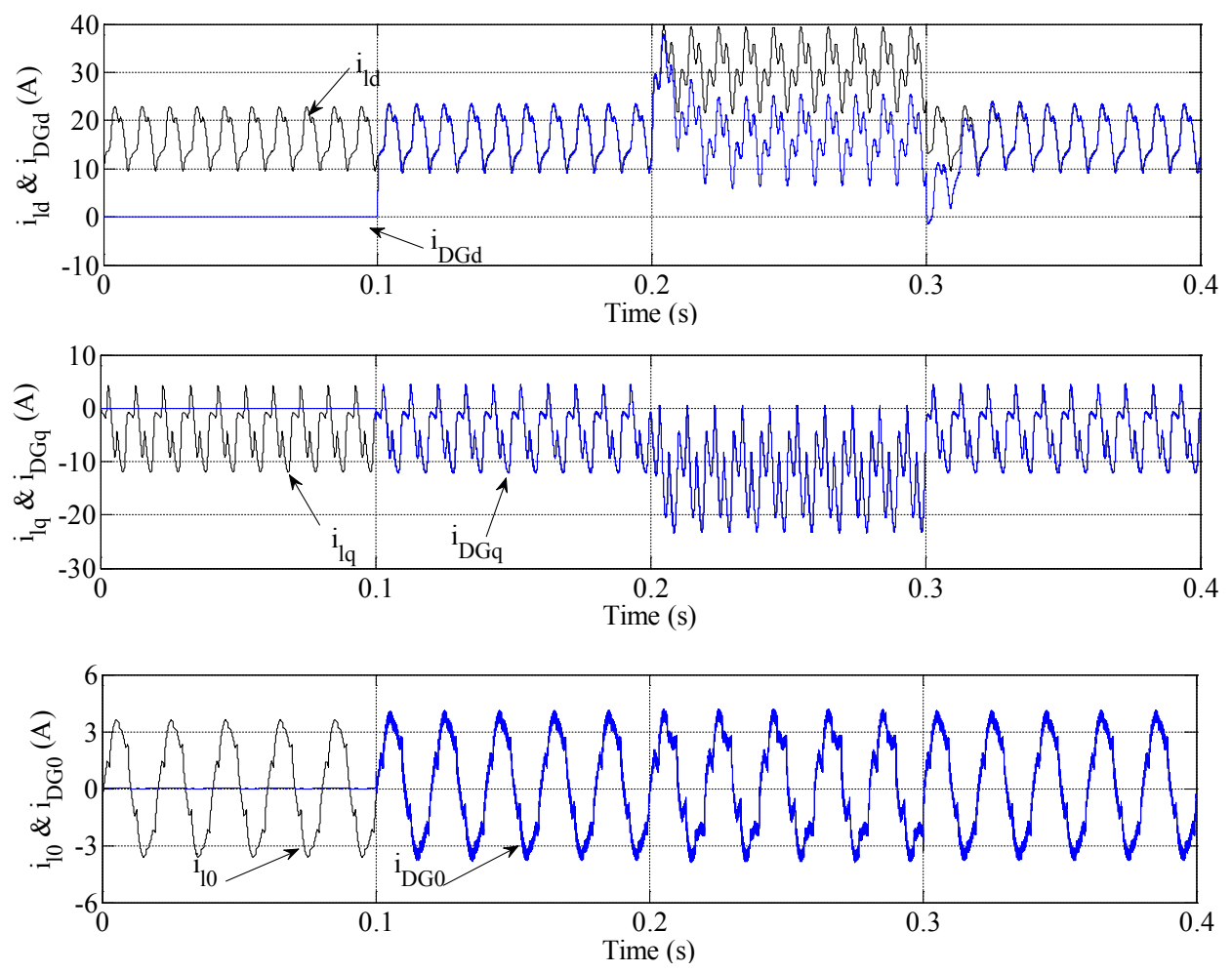

Figure 8. Load and DG unit currents in $d$-, $q$ - and 0 -axes during considered events.
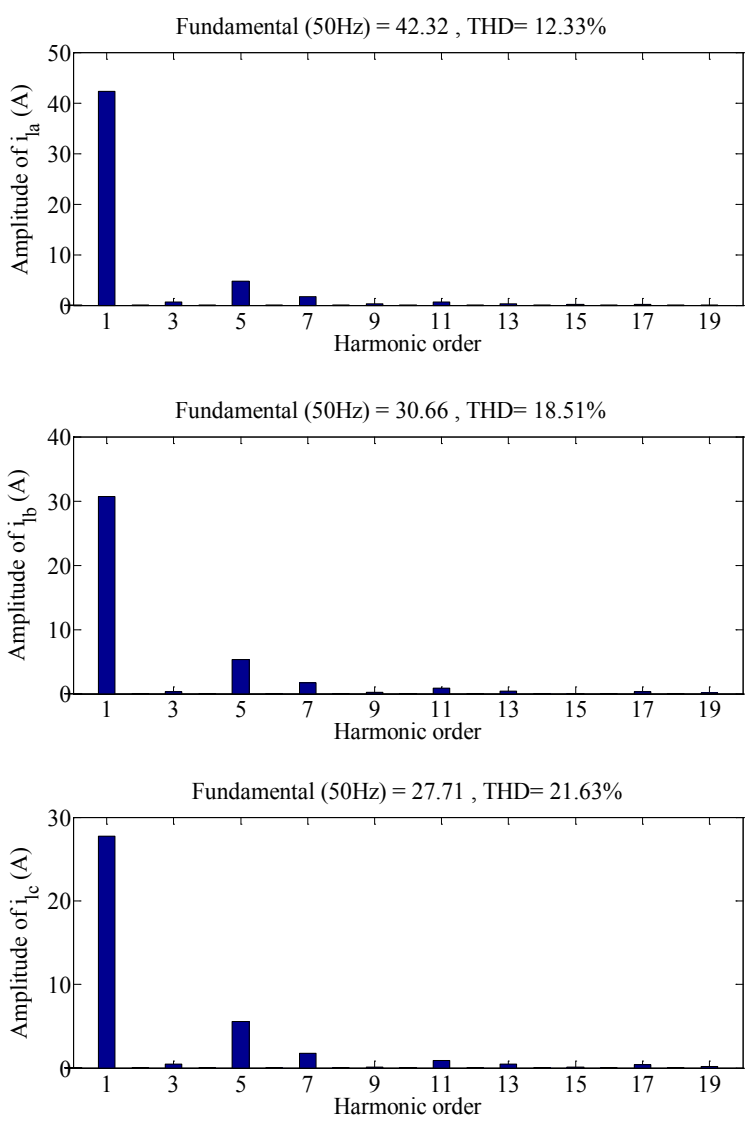

Figure 9. Spectrum of load current in phases $a, b$ and $c$. 

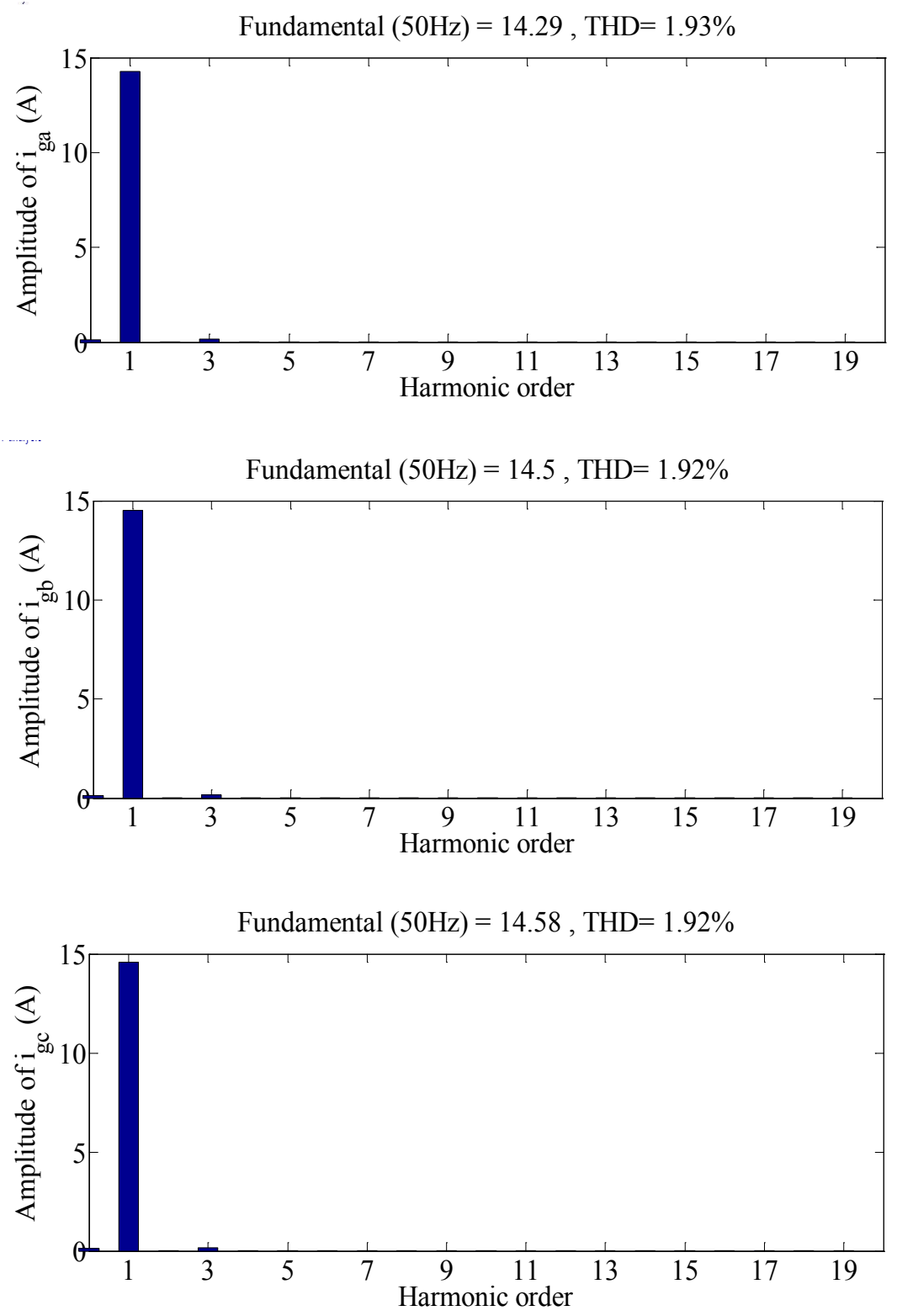

Figure 10. Spectrum of grid current in phases $a, b$ and $c$.

parison between this information verifies the capability of the proposed control strategy to compensate the harmonic currents generated by nonlinear loads.

One of the advantages of the proposed control strategy is its capability for correcting the power factor. As seen in Figure 11, the grid currents and PCC voltages are in phase in all three phases.

\section{Conclusion}

This paper has proposed a multifunctional control approach for connection of DG resources to 3P4W grids by means of four-leg converters. The in-detail modeling and appropriate control of the DG system by using an effective and simple technique have been precisely carried 

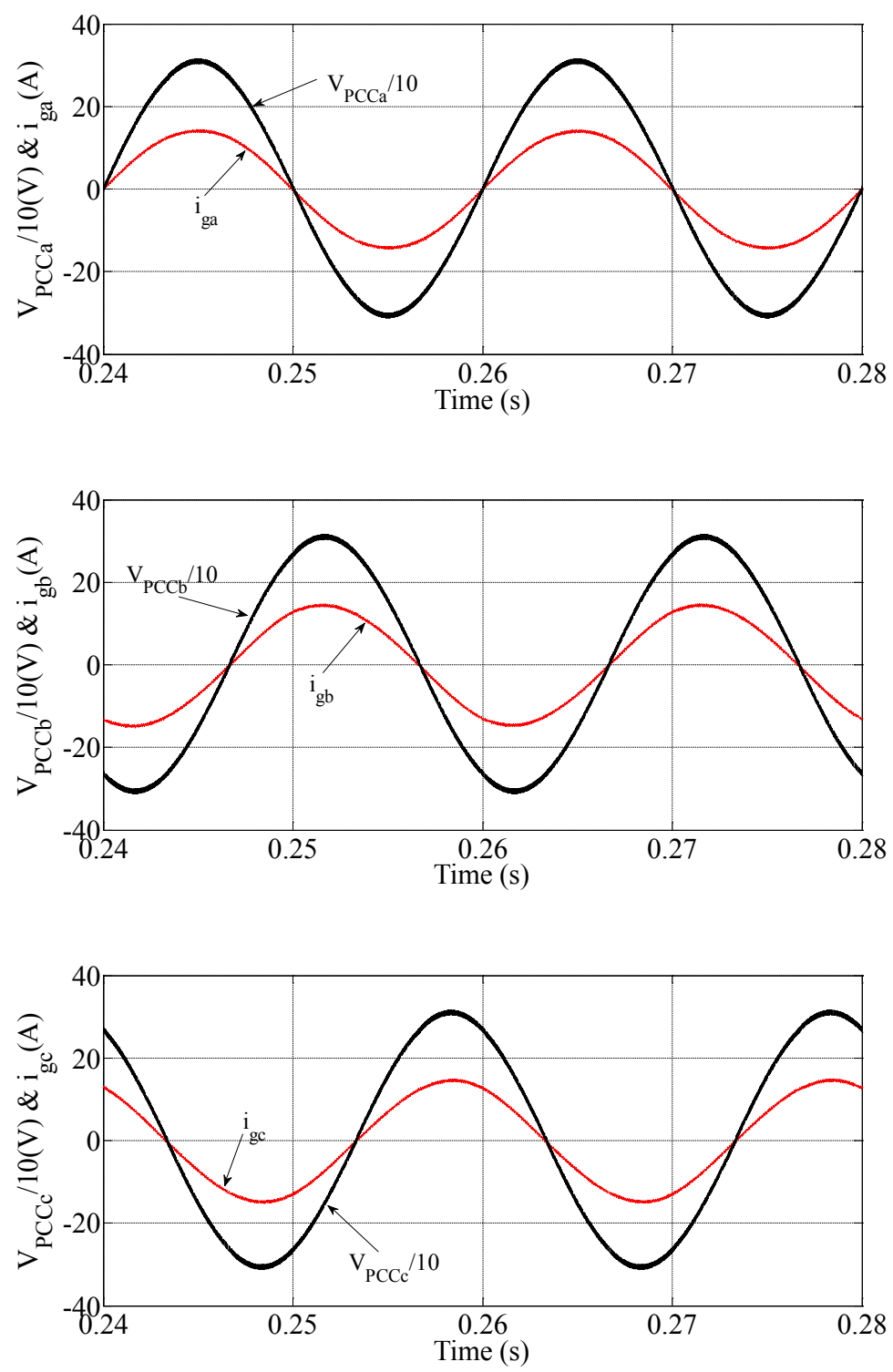

Figure 11. Grid currents and PCC voltages in phases $a, b$ and $c$ after connection of extra load.

out. By the use of the proposed approach, the converter has been utilized to perform harmonic compensation, reactive power compensation, unbalance compensation, grid neutral current elimination and active power injection. The main advantage of the proposed technique is the overshoot reduction and its damping during transientstate condition, and hence improving the system stability. The performance of the proposed control approach in both transient and steady-state operating conditions has been verified by simulation results. The suggested control approach of this paper can be utilized for connection of different kinds of DG resources to distribution grids in order to improve power quality indices.

\section{References}

1. Maaref M, Monsef H, Karimi M. A reliability model for a doubly fed induction generator based wind turbine unit considering auxiliary components. Indian Journal of Science and Technology. 2013 Sep; 6(9):5281-8.

2. Khani NG, Abedi M, Gharehpetian GB, Riahy GH. Analyzing the effect of wind farm to improve transmission 
line stability in contingencies. Indian Journal of Science and Technology. 2015 Jun; 8(11):1-6.

3. Roy NK, Pota HR, Hossain MJ. Reactive power management of distribution networks with wind generation for improving voltage stability. Renewable Energy. 2013 Oct; 58:85-94. https://doi.org/10.1016/j.renene.2013.02.030

4. Seyedalipour SS, Adabi J. An active control technique for integration of distributed generation resources to the power grid. International Journal of Electrical Power and Energy Systems. 2016 May; 77:353-59. https://doi.org/10.1016/j. ijepes.2015.11.072

5. IEEE, Standard 1547. Standard for interconnecting distributed resources with electric power systems; 2003.

6. Nadh AP, Kishore DR. Integration of PV based DG source in $\mathrm{AC}$ microgrid with interconnection to grid. Indian Journal of Science and Technology. 2015 Nov; 8(32):1-5.

7. Yao Z, Xiao L, Yan Y. Seamless transfer of single-phase grid interactive inverters between grid-connected and standalone modes. IEEE Transactions on Power Electronics. 2010 Jun; 25(6):1597-603. https://doi.org/10.1109/ TPEL.2009.2039357

8. Shahroudi MM, Mohamadian S, Naderi MS, Mahdavizadeh F. A novel reference current generation strategy for multifunction DG-grid interface, using C-RLS algorithm. International Transactions on Electrical Energy Systems. 2015 Nov; 25(11):2877-96. https://doi.org/10.1002/ etep. 1997

9. HeJ,Li YW, Munir MS. A flexible harmonic control approach through voltage-controlled DG-grid interfacing converters. IEEE Transactions on Industrial Electronics. 2012 Jan; 59(1):444-55. https://doi.org/10.1109/TIE.2011.2141098

10. Sawant RR, Chandorkar MC. Methods for multi-functional converter control in three-phase four-wire systems. IET Power Electronics. 2009 Jan; 2(1):52-66. https://doi. org/10.1049/iet-pel:20070232
11. Zeng Z, Yang H, Zhao R, Cheng C. Topologies and control strategies of multi-functional grid-connected inverters for power quality enhancement: A comprehensive review. Renewable and Sustainable Energy Reviews. 2013 Aug; 24:223-70. https://doi.org/10.1016/j.rser.2013.03.033

12. Yazdanpanahi H, Li YW, Xu W. A new control strategy to mitigate the impact of inverter-based DGs on protection system. IEEE Transactions on Smart Grid. 2012 Sep; 3(3):1427-36. https://doi.org/10.1109/TSG.2012.2184309

13. Cheng PT, Chen CA, Lee TL, Kuo SY. A cooperative imbalance compensation method for distributed-generation interface converters. IEEE Transactions on Industry Applications. 2009 Mar; 45(2):805-15. https://doi. org/10.1109/TIA.2009.2013601

14. Marei MI, El-Saadany EF, Salama MMA. A novel control algorithm for the DG interface to mitigate power quality problems. IEEE Transactions on Power Delivery. 2004 Jul; 19(3):138492. https://doi.org/10.1109/TPWRD.2004.829922

15. Cho GC, Jung GH, Choi NS, Cho GH. Analysis and controller design of static var compensator using three-level GTO inverter. IEEE Transactions on Power Electronics. 1996 Aug; 11(1):57-65. https://doi.org/10.1109/63.484417

16. Singh M, Khadkikar V, Chandra A, Varma RK. Grid interconnection of renewable energy sources at the distribution level with power-quality improvement features. IEEE Transactions on Power Delivery. 2011 Jan; 26(1):307-15. https://doi.org/10.1109/TPWRD.2010.2081384

17. Sarada S, Reddy B, Balaji K. Real-time implementation of multi-level inverter for 3P4W distribution network using ANFIS control. Indian Journal of Science and Technology. 2015 Nov; 8(30):1-6. https://doi.org/10.17485/ijst/2015/ v8i30/78761

18. Verdelho P, Marques GD. An active power filter and unbalanced current compensator. IEEE Transactions on Industrial Electronics. 1997 Jun; 44(3):321-8. https://doi. org/10.1109/41.585829 